\title{
Planning as the Base for Efficient Management of ICT

\author{
The case of ULPGC
}

\author{
Jacques Bulchand, Jorge Rodríguez \\ Universidad de Las Palmas de Gran Canaria \\ jbulchand@dede.ulpgc.es
}

\begin{abstract}
Challenges produced as a result of the vertiginous advance in computer and communication science are extremely difficult to meet, especially for public universities. In this paper, we propose a methodology for the development of strategic information system (IS) and information and communication technology (ICT) plans in higher education and we present the application of this planning procedure to the Las Palmas de Gran Canaria University. A formal planning process is needed in higher education to meet the needs of all agents participating in the universities. Thus, the proposed methodology is composed of nine steps and involves the whole of the university community, not just IS/ICT technicians. These nine phases, derived from strategic planning procedures, are preplanning, external environment assessment, internal evaluation, strategic interest themes identification, mission and vision statements declaration, strategic axes identification, goals and strategies definition, project and specific actions definition and implementation and evaluation. In this paper we also present in detail the process carried out in ULPGC using the proposed methodology and the results in "The Plan for InfoTech Systems and Communications ULPGC 2003-2006", which is at present in its implementation or execution phase.
\end{abstract}

Key words: Information systems, information and communication technology, strategic planning. 


\section{INTRODUCTION: THE NECESSITY FOR IS/ICT PLANNING}

Lately, we are seeing higher education institutions going though a series of very important changes. On one hand they are subject to growing economical restrictions. On the other, there is a vast necessity of information systems (IS) and information and communication technologies (ICT) in all the environments of university life (Bates, 2000).

Under this perspective, information systems and information and communication technologies (IS/ICT) development requires careful planning. This planning should involve the whole university community. Indeed, they should be given the chance to opine about which are the problems that must be attended in the short term and what should be the financial resources distribution.

Besides allowing participation, IS/ICT planning lets us achieve six goals (Andreu, Ricart and Valor, 1996; Cassidy, 1998; Ward and Griffiths, 1996). First, an alignment between the IS/ICT strategy and the corporate. Second, guaranteeing the necessary resources so that the ICT area is able to face rapidly changing environments. Third, finding an efficient and feasible structure for the IS/ICT area. Fourth, improving the communication between management and the IS/ICT technicians. Fifth, dealing with a critical and expensive organizational resource. And sixth, obtaining an organizational knowledge by doing the planning process.

\subsection{Barriers to IS/ICT Planning}

Although it may seem that the above stated goals are very important, it is verifiable that very few organizations carry out formal IS/ICT planning procedures. What is the reason for this behavior? Basically, the resistance to this kind of planning found in managers and in IS/ICT technicians.

IS/ICT technicians resist because organizations have tried to apply in this area every possible management technique, such as outsourcing, downsizing or total quality management. Unfortunately, results obtained have not really been significant. Due to this, technicians tend to be skeptical and consider each new initiative and strategy as a trend which is in vogue but which will shortly disappear (Boar, 2001).

Managers, on their hand are not favorable either to IS/ICT planning. They do not really see the impact that IS/ICT have and there is a credibility gap in ICT use. Plus, they do not view information as a business resource to be managed for long-term benefit, as economical and human resources are (Ward and Griffiths, 1996). 


\subsection{Problems When There is Not an IS/ICT Plan}

Once the main goals of the planning process and the main existing barriers to them have been defined, some authors describe the problems organizations that do not have strategic IS/ICT plans will face (Ward and Griffiths, 1996). First, there will be a loss of business opportunities and the organization will incur a competitive disadvantage in respect to competitors. Second, there will be a lack of integration between systems and inefficient management of data. This is duplication of efforts, lack of precision, delays and information not useful for business management. Third, development priorities will not arise from business needs. Instead, projects to be developed will arrive from available technologies and from the search of an application for them (Cassidy, 1998). These three kinds of problems should help convince managers about the need of carrying out IS/ICT planning processes.

\section{PLANNING METHODOLOGY}

We now propose a methodology to develop information systems and information and communication technology plans in higher education institutions. We base our work in the existing methodology for the development of strategic plans applying it to the information systems and technology area (Bates, 2000; Bryson, 1998; Bryson, 1995). Thus, we propose a methodology composed of nine phases that we now present.

Each of these phases requires a series of techniques and tools. These will be referred to in each of the phases although they will thoroughly described in next section.

\subsection{Preparation for Planning}

This phase can be considered previous to the planning process. Its main goals are three. To define why we are going to carry out the planning, to determine the exact process that is going to be used and to define the involved work teams.

\subsection{External Environment Assessment}

The second phase is external environmental assessment. Its main goal is to detect existing trends and to check their influence on the university being studied. In this phase, we obtain two of the SWOT matrix components: opportunities and threats. The techniques and tools to be used in this phase 
are other university IS/ICT plan examination, observation and in-depth interviews.

\subsection{Internal Evaluation}

The third phase is dedicated to internal evaluation. Its goal is to analyze current and under-developed IS, user perceptions, infrastructures, current human resources and economical resources dedicated in the last few years. As a result of this phase we will obtain strengths and weakness of the SWOT matrix. The techniques and tools to be used in this phase are several. Gibson and Nolan's model, value chain model, Rockart's critical success factors model, discussion groups, in-depth interviews, questionnaires, other university IS/ICT plan examination, detailed examination of all the existing documents regarding the IS/ICT area and direct observation.

\subsection{Strategic Interest Themes Identification}

The fourth phase is meant to identify strategic interest themes, which can be considered as the union of challenges and trends. Challenges appear formally expressed in the institution's strategic plan, if it exists, or in its SWOT matrix. Trends, on the other hand can be identified through the Delphi method and through in-depth interviews. Techniques to be used in this phase are four. Examination of the institution's strategic plan and its SWOT matrix as well as other university IS/ICT plans and articles by experts in the area, in-depth interviews, questionnaire and Delphi method.

\subsection{Mission and Vision Declaration}

The fifth phase is dedicated mission and vision statements declaration. Mission is a precise definition that justifies the existence of the organization's IS/ICT area and where functions provided by it to the rest of the organization is found. Vision is where the organization wants to arrive in the long-term. Techniques to be used in this phase are four. First, in-depth interviews. Second, examination of other university IS/ICT plans. Third, observation of tasks usually accomplished by IS/ICT staff. Last, the questionnaire that will be sent to the whole community.

\subsection{Strategic Axes Identification}

The sixth phase consists of strategic axes identification. These axes are a few pillars over which the future can be organized. When possible, they 
should be derived from the institution's strategic plan. Else, in-depth interviews must be used.

\subsection{Goals and Strategies}

In the seventh phase, goals and strategies are proposed for each of the axes defined. Usually there will be between three and five goals for each axis. Goals concerning IS, ICT and information management must be present. Techniques to be used are in-depth interviews, questionnaires, Delphi method and other university IS/ICT plan examination.

\subsection{Projects and Specific Actions Definition}

In the eighth phase, a series of projects and specific actions are defined for each of the strategies previously outlined. Each of them is assigned a budget, a responsible and one or more indicators that allow us to control them. These specific actions are derived from the questionnaires, interviews and observation of internal documents and from examination of other university IS/ICT plans. All of them will be validated in the Delphi method.

\subsection{Implementation and Evaluation}

The ninth and last phase is called implementation and evaluation. Its goal is to guarantee that proposed actions are put into practice and to evaluate obstacles found. In the evaluation phase we use the indicators that have been generated for each action. We suggest using the Balanced Scorecard, which allows us to get and integrated vision of all the indicators.

\section{FIELD WORK}

All through the developed proposal, we have pointed to several methods and techniques to be used in each of the phases. However, it is not necessary to develop them individually for each phase. Instead, carrying them out just once though the planning process is enough to achieve, simultaneously, all the intended goals. We now present each of the techniques and tools to be used, outlining an approximate proposal of when they should be developed.

\subsection{University Strategic Plan}

We have already mentioned that the best situation is when the university has a strategic plan and that it is aligned with the IS/ICT plan. In this case, 
the strategic plan and the IS/ICT plan will be developed in parallel. Thus the strategic plan will take into account the IS/ICT area, so challenges needed for strategic interest themes and strategic axes will be developed in the institution's plan.

If the strategic plan did not take into account specifically the IS/ICT area when developed, we will probably have to add a strategic axis specifically focused on systems and technologies. Last, if we do not have an institution's strategic plan at all, the strategic interest themes and the axes for the IS/ICT plan will have to be drawn from the external and internal analysis of the institution using other research techniques.

\subsection{Internal Documents}

Internal documents are an important source of information for internal evaluation and for mission and vision definition. Documents to be analyzed are the statutes and normatives and the IS/ICT area job post relation.

\subsection{Direct Observation}

Direct observation of the work carried out by the IS/ICT staff is useful to complete the results obtained from the examination of internal documents. With it, we also find out which are the tasks really done by the IS/ICT staff above what is officially stated.

\subsection{Other University IS/ICT Plans}

Examination of other university IS/ICT plans is one of the most useful information sources in the planning process. This is because the environment in all universities is fairly similar. If we do not have an institution's strategic plan, we will use this examination for the axes definition, too.

\subsection{Discussion Groups}

The main goal of discussion groups is to detect the problems associated with IS/ICT use in the university under study. Due to this it is a technique to be used during the internal evaluation phase. We understand discussion groups should not try to find solutions to problems, since in initial phases the main goal is to find out the current situation and not to solve existing problems. We also advise that ICT technicians do not participate in these groups. 
We propose carrying out a minimum of five discussion groups with university community members. Two would be dedicated to administrative staff, two to teachers and researchers and one to students.

\subsection{In-Depth Interviews}

In-depth interviews should be carried out to rectoral team members, department directors and faculty deans. Not all these members must be interviewed, since the number could be considerable. Instead we propose selecting a smaller number through a directed random selection process. The goals of the in-depth interviews are to validate problems detected, to detect perceptions and sensations that relevant university members have about the university's IS/ICT, to analyze what these members expect from the university IS/ICT and to find some solutions to the main problems already detected. These interviews should be carried out once we have ended and analyzed discussion groups.

\subsection{Questionnaire}

A questionnaire is sent to all members of the university community, and its main goals are to confirm problems that arose during the discussion groups, to allow all university members to take place in the elaboration of the plan, to find out the opinion that the community has about some trends that are happening and to help in defining goals and action plans.

\subsection{Delphi Method}

Last, we propose developing a Delphi method in the ending part of the planning process, when a first outlining of goals, strategies and action plans has already been made. In this case, we think the participants should be experts in university IS/ICT, relevant rectoral team members and some external members, such as experts from local government, nation-wide system experts or university IS/ICT suppliers.

\subsection{Analysis Tools}

We consider using three analysis tools in the IS/ICT planning process in universities: the value chain model, the critical success factors and Gibson and Nolan's model. 


\section{ULPGC IS/ICT PLAN}

We now describe the process taken to develop the Universidad de Las Palmas de Gran Canaria's (ULPGC) IS/ICT plan.

\subsection{Development of the ULPGC IS/ICT Plan}

We now describe the steps taken to validate this methodology through its application to ULPGC.

The proposed plan was developed in the eight months between November 2001 and June 2002. During this time a direct observation of the IS/ICT area of the university was carried out, and during the first four months internal documents were examined.

Five systems and technology plans of higher education institutions from the United States were examined. These five examined plans were obtained from the Internet and were those of Berkeley, MIT, University of Arizona, Penn State University and East Tennessee State University.

IS/ICT and institutional strategic plans were developed with a certain overlapping, so some degree of alignment was achieved. During November 2001, five discussion groups with non-expert users were carried out. The first two of them were with researchers and teachers. The next two were with administrative staff and the last one involved students.

From these discussion groups, a structured list of more than 120 items was created. These items were classified into 10 subjects, each item reflecting a problem detected by users or a wish about how IS/ICT should work.

Using these problems and the desires found in the discussion groups, a semi-structured questionnaire composed of 31 questions was elaborated. This questionnaire was used in a series of in-depth interviews that were carried out in December 2001 and January 2002. These in-depth interviews were carried out to 8 rectoral team members, 6 deans and 6 department directors, for a total of 20 interviews.

Last, in April 2002 two simultaneous processes started. On one hand, a questionnaire was sent out to all the members of the University. On the other hand, a Delphi method was developed.

This questionnaire was only filled using electronic media; basically the institution's web page. A total of 544 answers arrived: 234 from teachers and researchers, 143 from administrative staff and 167 from students.

For the Delphi method, an expert panel composed by 22 experts in IS/ICT from university and non-university environments was used. The first round took place in April and May 2002 and the second one in June 2002. In each of these rounds, experts where asked about three different items. First, 
trends in general environment and their possible influence in our university. Second, about the main goals to be carried out. Third, the actions needed to achieve the goals and qualitative and quantitative indicators for each of them. In the first round, economical and temporal estimations where asked for and in the second round a confirmation of these was required.

Also two of the three proposed tools were used, the value chain model and Gibson and Nolan's model. The critical success factors model was not used.

\subsection{ULPGC IS/ICT Plan}

To end this paper, we now present the main contents of the Information and Communication System and Technology Plan of the ULPGC. Following the proposed methodology, the Plan has been structured into four axes. In each of them goals have been defined. In each goal action plans are defined. For each plan an execution time has also been estimated (short, medium and long term). Last, for each action plan we have a series of concrete actions, with a budget and a timetable for those to be executed in 2003 .

\subsubsection{SWOT matrix}

From the analysis developed by IS/ICT heads, from the discussion groups and from other university IS/ICT plans, we got the main environment trends that affect the university's IS/ICT. The analysis was considered externally ( 2 threats and 8 opportunities were found) and internally ( 8 strengths and 20 weaknesses were found).

\subsubsection{Mission and vision}

We define the ULPGC mission as "Give University Community a stable, productive and efficient ICT environment that makes teaching and researching easier, provides services to university community and to society, and helps knowledge management processes".

Vision is defined as "We intend to place our University in the top-ten in the IS/ICT area in our country, at the same level as reference universities in our context. ULPGC should be innovative in its daily tasks and must promote information and knowledge society in its environment."

\subsubsection{Axes}

We found four axes in total. Three were derived from the institution's strategic plan, those related to teaching, researching and management and 
services to the community. The fourth axis is specifically for IS/ICT and has been called "Technology and Available Resources".

\subsubsection{Goals and actions}

A total of 12 goals were defined between the four axis previously mentioned. Each of these 12 goals has a series of actions. In total, we have proposed up to 60 actions and 36 indicators to evaluate them. The Plan is available for download (in English and Spanish) at http://www.ulpgc.es.

\section{CONCLUSIONS}

Using a systematic approach to the development of system and technology plans in universities can be a great aid to achieve a successful distribution of limited financial resources in an expansive area such as that related to new technologies. But a better resource distribution is also achieved. Other important results are also obtained. First, the whole university community participates in the process. Second, due to their participation, they get to know the plan.

Also, a few effects have to be taken care of. On one hand is the hangover effect. This is thinking to some stage that the objective of the planning process is to develop the plan, when the goal is to implement the plan. On the other, when implementing the plan, we discover our limitations, that is, we are able to think fast, but we execute very slowly.

\section{REFERENCES}

Andreu, R., Ricart, J.E., Valor, J. (1996). Estrategia y sistemas de información. Barcelona, Spain. McGraw-Hill, Interamericana de España, S.A.

Bates, A.W. (2000). Managing technological change. Strategies for college and university leaders. San Francisco (CA), EE.UU. Jossey-Bass Publishers.

Boar, B. (2001). The Art of Strategic Planning for Information Technology. New York (NY), USA. John Wiley \& Sons, Ltd.

Bryson, J.M. (1988). "A strategic planning process for public and non-profit organizations". Long Range Planning, 21(1), pp. 73-81.

Bryson, J.M. (1995). Strategic planning for public and nonprofit organizations (2a edición revisada). San Francisco (CA), USA. Jossey-Bass.

Cassidy, A. (1998). A practical guide to information systems strategic planning. Boca Raton (FL), USA. St. Lucie Press.

Ward, J., Griffiths, P. (1996). Strategic planning for information systems. Chichester, UK. John Wiley \& Sons. 